\title{
SENSORIAMENTO REMOTO NA AVALIAÇÃO DAS CARACTERÍSTICAS GEOMORFOLÓGICAS PARA A IDENTIFICAÇÃO DA SENSIBILIDADE AMBIENTAL A DERRAMES DE ÓLEO: BAIXO CURSO DO RIO PIRACICABA - SP
}

\author{
REMOTE SENSING TO EVALUATE GEOMORPHOLOGICAL FEATURES FOR THE \\ ENVIRONMENTAL SENSITIVITY TO OIL SPILLS: LOWER COURSE OF THE RIVER \\ PIRACICABA (SP)
}

\author{
Daniela Ferreira RIBEIRO ${ }^{1}$, Cenira Maria LUPINACCI ${ }^{2}$, Paulina Setti RIEDEL ${ }^{1}$ \\ ${ }^{1}$ Departamento de Geologia Aplicada, Instituto de Geociências e Ciências Exatas, Universidade Estadual Paulista. Rio Claro, SP, \\ Brasil.Email: danifebeiro@gmail.com; psriedel@rc.unesp.br \\ ${ }^{2}$ Departamento de Planejamento Territorial e Geoprocessamento, Instituto de Geociências e Ciências Exatas, Universidade Estadual \\ Paulista. Rio Claro, SP, Brasil. Email: cenira@rc.unesp.br

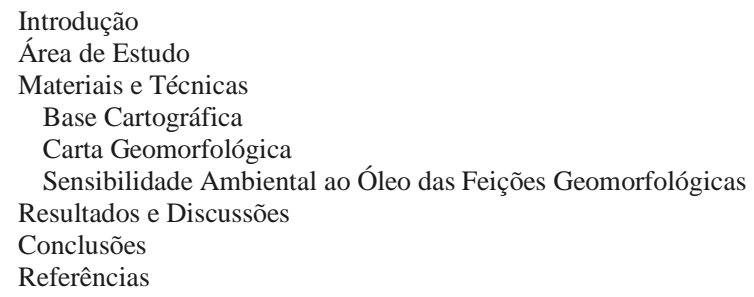

\begin{abstract}
RESUMO - As Cartas de Sensibilidade Ambiental a Derrames de Óleo constituem-se em ferramentas para o planejamento de contingência e avaliação de danos causados por óleo, sendo amplamente utilizadas nos ambientes costeiros, entretanto apresentam lacunas para os ambientes fluviais. O principal objetivo deste trabalho é contribuir com a avaliação da sensibilidade ambiental ao óleo dos ambientes fluviais, através da identificação e mapeamento das feições geomorfológicas de origem fluvial, realizada por meio da interpretação visual em imagens orbitais. As feições foram analisadas quanto à sua sensibilidade considerando parâmetros definidos por bibliografias internacionais que utilizam critérios como grau de exposição, permeabilidade e aspectos relacionados à dinâmica fluvial, com ênfase ao potencial acumulativo ou erosivo. A área de estudo apresenta um alto índice de sensibilidade das feições geomorfológicas a derrames de óleo, devido à presença, em grande parte de sua extensão, de depósitos aluviais, diques marginais e terraços fluviais. Destaca-se ainda a presença de diversos canais fluviais afluentes do canal principal, com baixa energia, o que também configura um alto índice de sensibilidade. As regiões que apresentam os menores índices são representadas pelas áreas próximas às regiões urbanas, marcadas por margens construídas, com a presença de paredões concretados e pela presença de soleira fluvial. A caracterização geomorfológica, por meio de imagens de sensoriamento remoto, permite uma análise expedita, o que é relevante num país de dimensões continentais como o Brasil e pode ser detalhada por trabalhos de campo, em regiões de maior complexidade.
\end{abstract}

Palavras-chave: Mapeamento Geomorfológico, Sensibilidade Ambiental a Derrames de Óleo, Cartas SAO.

\begin{abstract}
The Environmental Sensitivity Index mapping constitute an important tool for contingency planning and assessment of damage caused by oil spills. These maps widely used in coastal environments, where the methodology is well defined, present gaps for river environments. The main objective of this work is to contribute to the assessment of environmental sensitivity to oil of river environment by identifying and mapping geomorphological features of fluvial origin, carried out through visual interpretation of satellite images. Once identified, the features were analyzed for their sensitivity, considering parameters defined by international references, which are based on criteria such as degree of exposure, permeability, aspects related to river dynamics, as cumulative or erosive potential. The study area has a high sensitivity index of geomorphological features to oil spills due to the presence, for much of its length, of alluvial deposits, alluvial dikes and river terraces. It also highlights the presence of several tributaries rivers in the main channel, with low energy, which also sets a high sensitivity index. The regions with the lowest index are represented by areas close to urban areas, marked by built margins, with the presence of concreted walls and the presence of river sill. The geomorphological characterization through satellite images allows an expedited analysis, which is relevant in a country with continental dimensions as Brazil and can be detailed by fielwork in regions with greater complexity.
\end{abstract}

Keywords: Geomorphology mapping, Environmental Sensitivity to Oil, Environmental Sensitivity Charts.

\section{INTRODUÇÃO}

O petróleo é considerado uma importante fonte de energia utilizada atualmente pelo homem. Entretanto, sua intensa utilização acarreta riscos ao meio ambiente devido à possibilidade de acidentes envolvendo vazamentos de óleo no processo de transporte de hidrocarbonetos. Os principais tipos de transporte dividem-se em terrestres, como o ferroviário, rodoviário e dutoviário, e transportes aquaviários, que utilizam as vias hídricas para navegação. Os desastres ocorrem principalmente devido a colisões de navios transportadores, rompimento de dutos, explosões em plataformas e acidentes envolvendo veículos transportadores.

Dentro desse contexto, as Cartas de Sensibilidade Ambiental a Derrames de Óleo 
(Cartas SAO) constituem um importante instrumento para o planejamento de contingências e avaliação de danos causados pelos vazamentos. De acordo com Jensen et al. (1998), as Cartas SAO representam importantes instrumentos de planejamento e resposta a vazamentos de óleo, cujo objetivo é a localização de áreas mais sensíveis ao óleo, visando à proteção dessas áreas e estabelecimento de estratégias adequadas de limpeza, reduzindo os possíveis impactos ambientais e sociais.

O conceito das cartas de sensibilidade ambiental evoluiu a partir da década de 1970, período em que os Estados Unidos começaram a desenvolvê-las como elemento essencial aos planos de contingência para a proteção dos recursos naturais.

No Brasil, o Ministério do Meio Ambiente elaborou um documento intitulado "Especificações e normas técnicas para elaboração de cartas de sensibilidade ambiental para derramamentos de óleo" que apresentou um índice de sensibilidade do litoral (ISL) adaptado às condições dos ambientes brasileiros, com uma escala de variação crescente, de 1 a 10, baseado no manual norteamericano elaborado pelo NOAA (National Oceanic and Atmospheric Administration). As Cartas de Sensibilidade fornecem além do índice de sensibilidade dos diversos ambientes, informações sobre os aspectos bióticos e socioeconômicos, que são representados por ícones específicos.

Atualmente, tem-se um satisfatório levantamento da sensibilidade ambiental ao derramamento de óleo bruto e seus derivados em ambientes litorâneos e um incipiente levantamento para as águas interiores. Segundo Braun \& Oliveira (2003), os estudos realizados sobre sensibilidade ambiental focavam-se prioritariamente nas regiões costeiras devido às dimensões dos acidentes nestas regiões.

Após os acidentes envolvendo ambientes terrestres ocorridos no Paraná, nos anos de 1999 e 2000, bem como o aumento de acidentes envolvendo veículos de transporte de óleo e derivados, verificou-se a necessidade de um maior conhecimento da sensibilidade ambiental das áreas terrestres, que não eram amplamente exploradas, pois eram consideradas pouco significativas. Ainda, segundo os autores, os mapas de sensibilidade ambiental das regiões terrestres devem ser priorizados, pois se constituem em importantes ferramentas para auxiliar a reduzir as consequências ambientais em caso de vazamentos de petróleo e orientar os esforços de contenção, limpeza e remoção pela identificação da sensibilidade dos ecossistemas terrestres, seus recursos biológicos e atividades socioeconômicas que caracterizam a ocupação dos espaços e o uso dos recursos naturais.

No contexto de águas interiores encontramse os ambientes fluviais, representados por rios de diferentes portes e reservatórios. Os estudos envolvendo a sensibilidade ambiental ao óleo em ambientes fluviais apresentam-se com maior destaque em publicações internacionais, destacando-se os mapeamentos realizados por Hayes et al. (1995, 1997), Zengel et al. (2001), para rios e córregos nos EUA e Mendoza-Cantú et al (2011), para os rios mexicanos Coatzacoalcos e Tonalá (sudeste do estado de Vera Cruz).

Estes consistem em documentos elaborados para o NOAA com base no sistema de classificação e na metodologia de mapeamento utilizada para a costa norte-americana. Apresentam um sistema com escala de sensibilidade também com variação de 1 a 10 (10 maior sensibilidade) com cores padronizadas, para o mapeamento de ambientes lacustres, estuarinos e fluviais (Costa et al. 2015). No presente trabalho, os índices de sensibilidade ao óleo dos sistemas fluviais serão denominados de ISF (Índice de Sensibilidade Fluvial).

No Brasil, a primeira metodologia relacionada à sensibilidade ambiental ao óleo em ambientes fluviais foi desenvolvida por Araújo et al. (2006) para os rios de grande porte amazônicos de Manaus e Coari. A partir das informações das feições fluviais amazônicas e de adaptações da metodologia proposta pelo Ministério do Meio Ambiente, em 2002 (MMA, 2002), para ambientes costeiros, desenvolveu-se um índice de sensibilidade fluvial com variação de 1 a 10 ( 1 menor sensibilidade e 10 maior), também baseado nos estudos desenvolvidos nos EUA.

Beaumord \& Ferreira (2008) realizaram um mapeamento de sensibilidade ambiental focado em outra realidade brasileira, nos cursos de 
água da bacia do rio Canhanduba, um rio localizado no município de Itajaí, em Santa Catarina.

Neste local foi instalada uma base de distribuição da Petrobras Transporte S/A TRANSPETRO, de onde se distribuem diversos dutos. A realização do mapeamento e a obtenção dos Índices de Sensibilidade Ambiental basearam-se nas informações da publicação "Especificações e Normas Técnicas para a Elaboração de Cartas de Sensibilidade Ambiental para Derramamentos de Óleo”, do Ministério do Meio Ambiente do ano de 2002.

Atualmente, as Cartas SAO produzidas para o ambiente fluvial não enfatizam a importância da realização de um mapeamento geomorfológico como subsídio direto para a sua elaboração, entretanto esta ferramenta deve ser priorizada, visto que os ambientes fluviais se constituem em áreas de complexa estruturação, sendo as informações a respeito da dinâmica dos rios fundamental para a compreensão da dinâmica do óleo. De acordo com Pavlopoulos, et al. (2009), a geomorfologia e, particularmente o mapeamento geomorfológico, tem a capacidade de identificar e analisar as formas de relevo, bem como, associá-las aos processos de evolução superficial e subterrânea.

Desta forma, o mapeamento geomor- fológico, que neste trabalho é especificamente direcionado ao reconhecimento e classificação das feições fluviais, pode funcionar como subsídio para a compreensão da dinâmica de transporte do óleo ao longo dos cursos d'água e de suas margens. Além disso, as diferentes feições fluviais tendem a estabelecer correlação com a biota existente no ambiente, fato que é importante para a avaliação da sensibilidade ambiental.

Considerando essas premissas, o principal objetivo do presente trabalho é demonstrar a importância do mapeamento geomorfológico das feições fluviais como subsídio para a construção de Cartas SAO, especificamente para o mapeamento dos índices de sensibilidade ambiental ao óleo, visto que as características geomorfológicas são imprescindíveis na análise do comportamento do óleo nestes ambientes, contribuindo diretamente para a identificação das áreas sensíveis.

Cabe salientar que as Cartas SAO, segundo MMA (2002), são compostas pelos índices de sensibilidade ao óleo, que são inerentes ao meio físico, pelas informações bióticas e socioeconômicas. Assim, este trabalho contribui somente com a discussão de uma das importantes variáveis da Carta SAO, integrante do meio físico.

\section{ÁREA DE ESTUDO}

Para a realização do presente trabalho foi selecionada como área de estudo o setor próximo ao fundo de vale do baixo curso do Rio Piracicaba, que é um rio de médio porte, localizado na região central do estado de São Paulo, entre a cidade de Piracicaba e o distrito de Artemis, entre as coordenadas $22^{\circ} 39^{\prime} 31$ 72" e $22^{\circ} 42^{\prime} 22^{\prime \prime}$ de latitude Sul e $47^{\circ} 53 ' 3711^{\prime \prime}$ e $47^{\circ} 36^{\prime} 46$ 65" de longitude Oeste (Figura 1).

Segundo o Instituto de Pesquisas Tecnológicas do Estado de São Paulo - IPT (1981), em relação às características geomorfológicas, a região localiza-se na Zona do Médio Tietê, no interior da Depressão Periférica Paulista. Segundo este mapa geomorfológico, ocorrem na área de estudo, em sua grande porção central, as colinas médias com predominância de "interflúvios, topos aplainados, vertentes com perfis retilíneos e convexos". $\mathrm{Na}$ porção oeste e leste há predomínio de colinas amplas que se caracterizam por "interflúvios, topos extensos e aplainados, vertentes com perfis retilíneos e convexos" e um pequeno trecho de planície aluvial, marcado por "terrenos baixos e mais ou menos planos, junto às margens dos rios, sujeitos periodicamente a inundações”. Na porção leste ocorre a presença de morrotes alongados e espigões, em que há "interflúvios sem orientação preferencial, topos angulosos e achatados, vertentes ravinadas com perfis retilíneos”.

Em relação às características geológicas, a área de estudo encontra-se na Bacia Sedimentar do Paraná, na qual está incluída a maior parte do Estado de São Paulo (IPT, 1981). Segundo este mapa, ocorrem na área de estudo as seguintes litologias: a) Formação Irati, na região leste, constituída por "siltitos, argilitos e folhelhos sílticos de cor cinza clara a escura, folhelhos pirobetuminosos, localmente em alternância rítmica com calcários creme, silicificados e restritos níveis conglomeraticos, membro pelítico muito persistente na base”; b) Formação Corumbataí, em grande parte da área, caracte- 
rizada por depósitos possivelmente marinhos de planícies de maré, incluindo argilitos, folhelhos e siltitos cinza, arroxeados ou avermelhados, com intercalações de bancos carbonáticos, silexíticos e camadas de arenitos finos; c) Formação Pirambóia, na região central e oeste do setor estudado, composta por arenitos finos a médios, avermelhados, síltico-argiloso, de estratificação cruzada ou plano-paralela, níveis de folhelhos e arenitos argilosos de cores variadas e raras intercalações de natureza areno-conglomerática; d) Intrusivas Básicas, na porção leste com presença de soleiras diabásicas, diques básicos em geral incluindo diabásios, dioritos pórfiros, microdioritos pórfiros, lamprófiros, andesitos, monzonitos pórfiros e traquiandesitos; e) Sedimentos aluvionares, no setor oeste, caracterizados por areias inconsolidadas de granulação variável, argilas e cascalheiras fluviais subordinadamente, em depósitos de calha e/ou terraço.
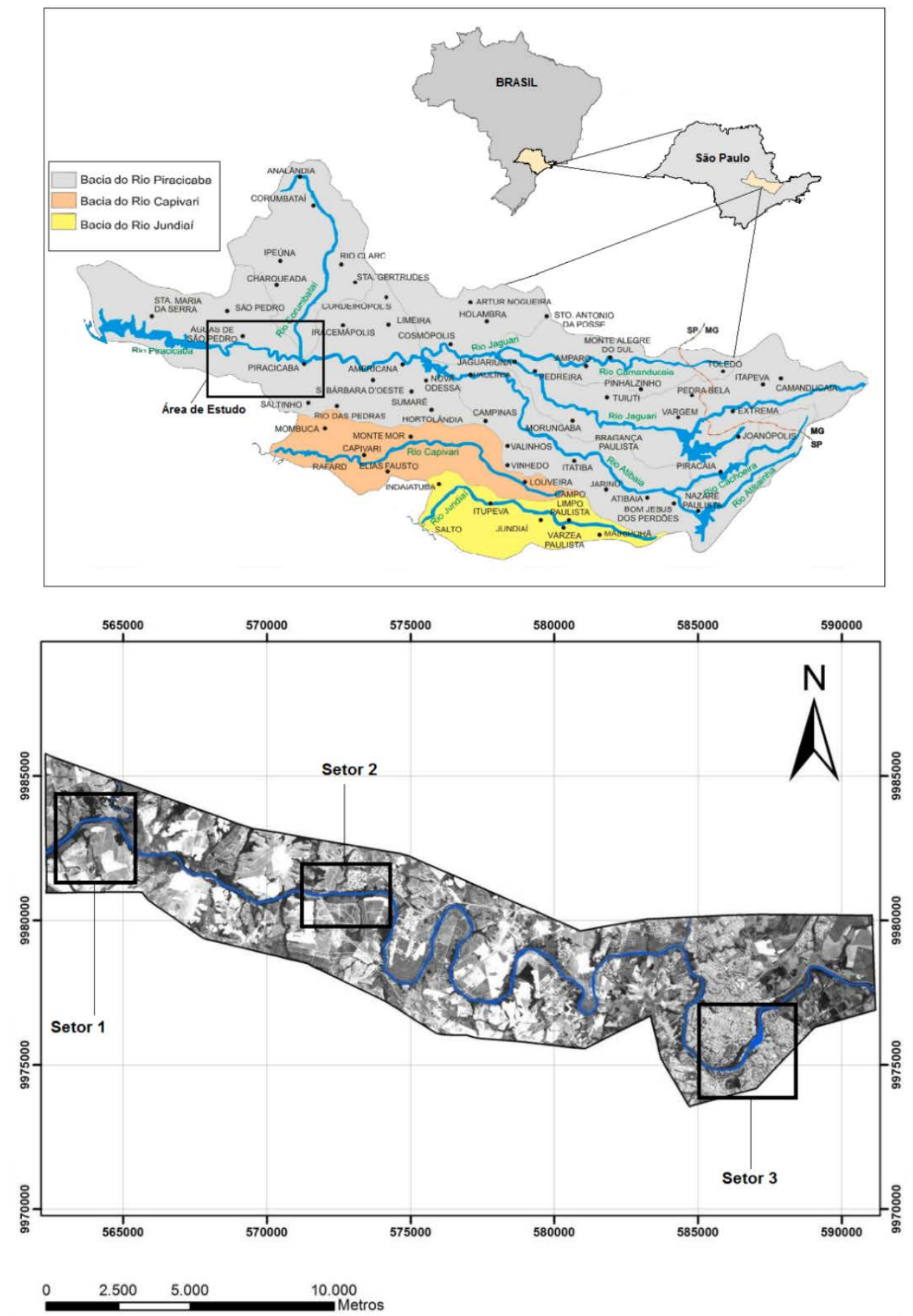

Figura 1 - Mapa representativo da área de estudo e respectivos setores abordados, lançados sobre imagens aéreas.

Considerando ainda que as condições climáticas interferem diretamente na dinâmica fluvial, convém enfatizar que, de acordo com
Prado (2004), o clima da região é considerado de transição entre os climas tropical e subtropical.

Segundo Ayoade (1986), na classificação de 
Köppen, a região é caracterizada como clima tipo Cwa.

A média pluviométrica anual da bacia do Rio Piracicaba é de $1440 \mathrm{~mm}$, sendo a média mensal do período seco, que vai de abril a setembro, inferior a $20 \mathrm{~mm}$ e do período úmido, entre outubro e março, em torno de $300 \mathrm{~mm}$. A vegetação da área, segundo Cabral (2003), foi caracterizada por floresta estacional semide- cidual, porém, atualmente essa vegetação encontra-se bastante degradada, dando lugar à monocultura intensiva de cana-de-açúcar e plantações de eucaliptos.

Em alguns setores das margens fluviais, a presença de resquícios de mata, nesse caso ripária, também se constituiu em fato importante para a avaliação da sensibilidade ambiental ao óleo.

\section{Base Cartográfica}

A base cartográfica da área de estudo, necessária para a realização dos demais mapeamentos, foi organizada a partir da coleta de cartas topográficas. As folhas utilizadas foram: São Pedro (SF-23-M-III-1) e Piracicaba (SF-23-Y-A-IV-2), em escala 1:50.000, datadas de 1969, com equidistância das curvas de nível de 20 metros, obtidas através do site do Instituto Brasileiro de Geografia - IBGE. Essa escala de trabalho justifica-se em função da dimensão da área a ser estudada e também por, em um país de dimensão continental e densa rede de drenagem, ser importante buscar sistemáticas de trabalho que permitam o mapeamento de amplas áreas.

Delimitou-se a área de estudo através da curva de nível correspondente a $60 \mathrm{~m}$ a partir do Rio Piracicaba. Desta forma, para a realização do mapeamento, considerou-se a faixa de terrenos cobertos pelas três primeiras curvas de nível a partir do curso d'água.

\section{Carta Geomorfológica}

Para a realização do mapeamento geomorfológico, foram utilizadas imagens orbitais da área provenientes do satélite SPOT5 , com resolução de 2,5m, cedidas pela Secretaria do Meio Ambiente do Estado de São Paulo, referentes ao mês de junho de 2010. As feições foram identificadas tendo por base as orientações de Cunha (2001) adaptadas das propostas de Tricart (1965) e Verstapen \& Zuidam (1975) a partir da seleção de símbolos adequados à representação geomorfológica, considerando os princípios da gestão ambiental.

Tricart (1965) afirma que as cartas geomorfológicas detalhadas devem conter as seguintes informações: morfometria, morfografia, morfogênese e cronologia. A morfometria compreende os atributos geométricos da forma de relevo e são fundamentais na apreensão de sua estrutura morfológica. A morfografia é representada através de símbolos que localizam e especializam as formas de relevo, representando a extensão e os processos que as originaram, bem como, o momento em que as formas se desenvolveram, identificando a morfogênese e a cronologia.

Assim, cada forma identificada na área de estudo foi agrupada segundo sua origem em grandes grupos de modelados, sendo feições hidrográficas, representadas por canais fluviais, presença de erosão fluvial lateral e lagos; formas de acumulação, com presença de depósitos aluviais, diques marginais, terraços fluviais, margens deposicionais e barras fluviais; e modelado de entalhe, marcado por margens erosivas e fundos de vale (característicos de formato "em V" e planos).

$\mathrm{O}$ mapeamento abrangeu as principais feições geomorfológicas de origem fluvial da área e, a partir desta análise, buscou-se avaliar o seu significado em termos de sensibilidade ambiental a derrames de óleo. Para uma correta identificação das feições vinculadas à deposição fluvial, principalmente as barras, optou-se por realizar o mapeamento geomorfológico em imagem de período de vazante, considerando que, com as águas mais baixas, as áreas de sedimentação seriam passíveis de serem visualizadas.

A Figura 2A apresenta as feições geomorfológicas barras fluviais, margem erosiva e margem deposicional. As barras fluviais foram identificadas por manchas brancas ocasionadas pela ausência de vegetação, posicionadas nas margens fluviais.

As margens erosivas são caracterizadas pelo aspecto íngreme das margens, indicando processos de erosão fluvial lateral e as margens deposicionais são marcadas pela presença de 
setores com manchas brancas ou cobertas por vegetação, cuja morfologia indica deposição, mas cuja dimensão impede seu mapeamento como polígono.

A Figura 2B apresenta a localização de um

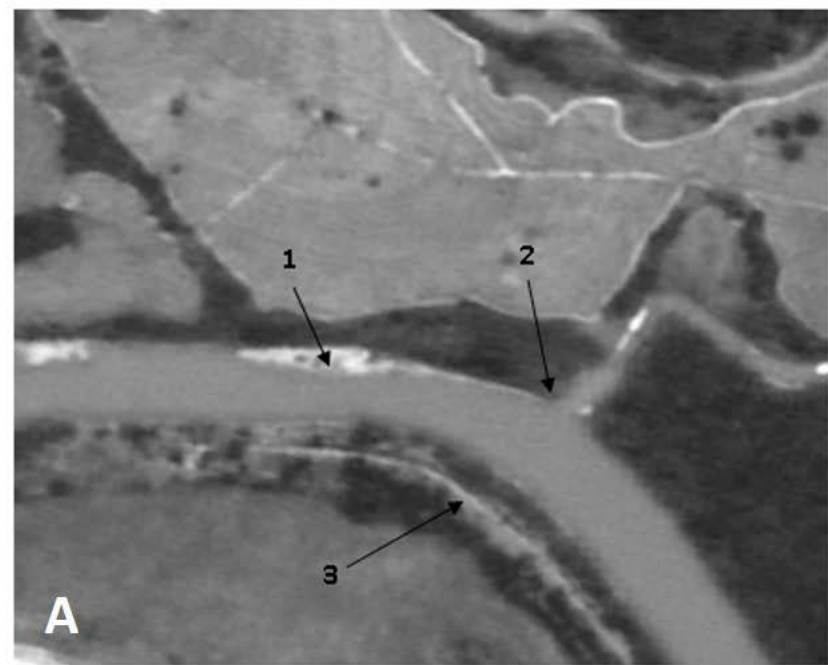

depósito aluvial, identificado devido as diferentes texturas de vegetação entre as planícies de inundação, com textura grumosa e coloração mais escura, e a vegetação das vertentes, com textura lisa e coloração mais clara.

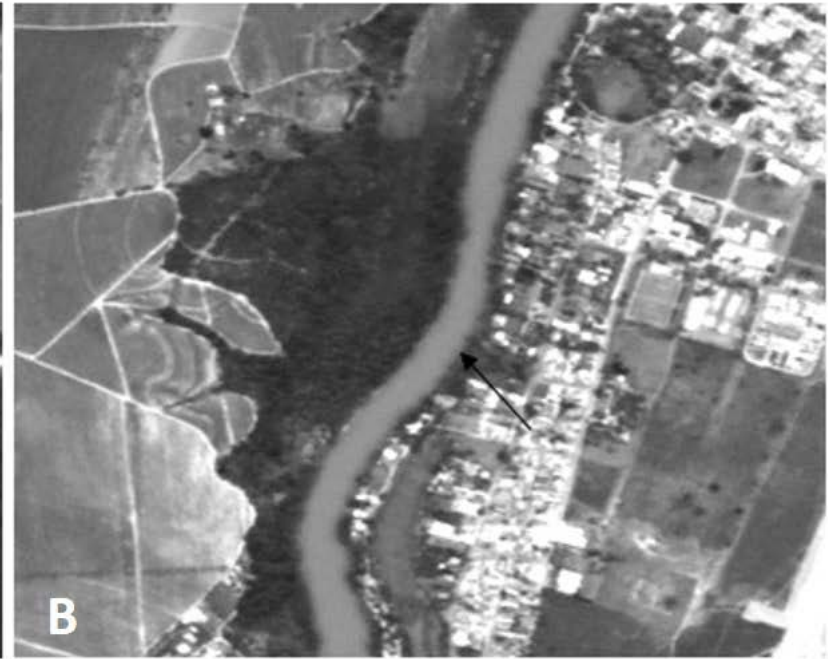

Figura 2 - A) Feições geomorfológicas encontradas na região de estudo: 1) Barras Fluviais, 2) Margem Erosiva, 3) Margem Deposicional; B) Identificação de depósito aluvial

A Figura 3A representa os aspectos morfológicos utilizados na identificação de um depósito fluvial com ausência de vegetação ou vegetação herbácea. Apresenta-se em tons de cinza mais escuro que ocorrem devido à presença de águas durante as cheias, e textura mais lisa do que áreas recobertas por vegetação de porte florestal. A Figura 3B representa um dique marginal, identificado pela localização próxima às margens do rio, com formação estreita, alongada e elevada, com coloração cinza escura.
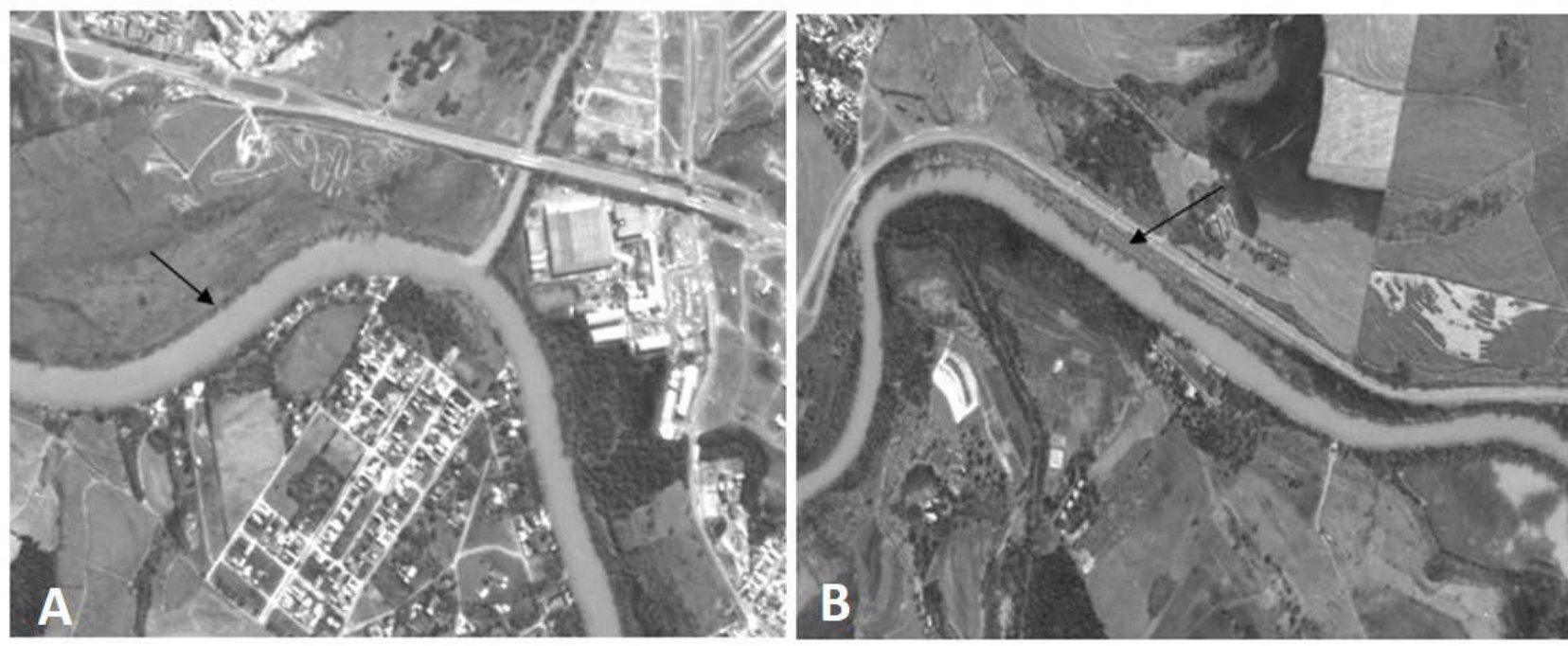

Figura 3 - A) Identificação de depósito fluvial com ausência de vegetação; B) Identificação de dique marginal.

A Figura 4A apresenta um dique marginal antigo, identificado devido a presença de diques ao lado de depósitos aluviais, com forma alongada e coloração em tons de cinza médio a claro. Na Figura 4B identificam-se terraços fluviais, determinados pela coloração em tons de cinza claro e posição topográfica mais elevada do que as áreas de inundação atual. Encontram-se ao lado dos depósitos aluviais.
Devido à resolução espacial da imagem orbital, foi possível identificar certos depósitos fluviais nas margens das pequenas drenagens.

Nos locais em que não foi viável a criação de um polígono para delimitar os depósitos, optou-se por representar as formas dos fundos de vale por símbolos, considerando que tais feições são relevantes na classificação da sensibilidade ambiental. 

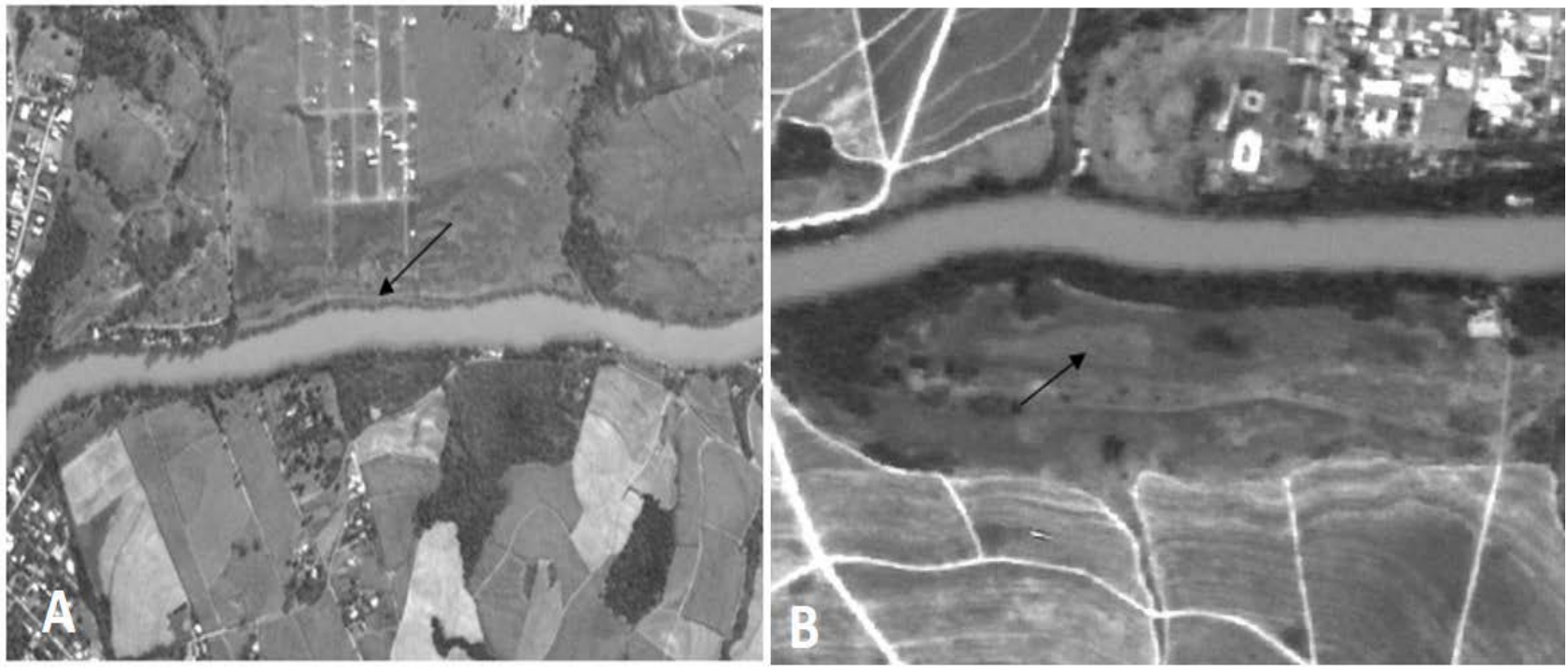

Figura 4 - A) Identificação de dique marginal antigo; B) Identificação de terraço fluvial.

Os modelados foram identificados como os fundos de vale em "V" e planos. Os fundos de vale em "V" foram identificados na imagem orbital devido à presença de canais com nítida característica de incisão, de aprofundamento da calha, normalmente sem nenhuma vegetação concentrada em suas margens. Os fundos de vale planos apresentavam fundo achatado, normalmente com coloração mais escura em função de área de inundação e muito comumente com vegetação em suas margens.

A partir da identificação destas feições, foi realizada a vetorização e edição dos dados através do software ArcGIS 9.3 (ESRI, 2012). As feições geomorfológicas foram classificadas em pontos, linhas e áreas e, a partir desta classificação, foram criados arquivos vetoriais (shapefile) no ArcCatalog para cada elemento representativo do relevo. A construção das simbologias baseou-se na proposta de Paschoal et al. (2010) para mapeamentos geomorfológicos utilizando o ArcGIS 9.3. Os elementos relacionados às áreas de acumulação de planície e terraço fluvial foram identificados por meio de áreas. As feições como fundos de vale planos e em "V", margens deposicionais (cuja dimensão não permitia a individualização das áreas, na escala de trabalho), margens erosivas e barras fluviais foram representadas por vetores configurados como linhas. Para a representação da erosão fluvial lateral utilizouse da ferramenta de vetorização configurada como linha, pois este tipo de vetor possibilita dentro do software ocultar a linha e trabalhar apenas com a sua finalização, que é representada por um símbolo que pode ser modificado de acordo com a sua utilização.

\section{Sensibilidade Ambiental ao óleo das Feições Geomorfológicas}

A classificação do índice de sensibilidade das feições geomorfológicas e a construção da legenda basearam-se nas orientações de Araújo (2006) e Hayes et al. (1995, 1997). A legenda foi elaborada utilizando as cores padronizadas propostas pela metodologia NOAA, bem como o índice de sensibilidade ambiental, cuja variação é de 1 , representando a menor sensibilidade, a 10 , representando a maior sensibilidade. Os critérios de mapeamento e seus respectivos índices de sensibilidade, denominados aqui de Índices de Sensibilidade Fluvial (ISF) estão apresentados na figura 5

As margens construídas, apresentam menor índice de sensibilidade, pois se constituem em estruturas artificiais, não se apresentando dificuldades relacionadas às operações de limpeza do óleo. As soleiras fluviais, também possuem baixa sensibilidade ambiental, pois constituem-se em ambientes em constante exposição à ação do hidrodinamismo, sendo incapazes de acumular óleo de forma significativa, fato que facilita a limpeza desse ambiente.

De acordo com Araújo (2006), as barras fluviais apresentam pequena extensão e maior facilidade de limpeza se comparada a outros ambientes que retêm água. A sensibilidade destes ambientes, porém também depende da granulometria do material depositado. 


\begin{tabular}{|c|c|}
\hline ISF & Feições \\
\hline $\mathbf{1}$ & Margens Construídas \\
\hline $\mathbf{2}$ & Soleiras Fluviais \\
\hline $\mathbf{5}$ & Barras Fluviais \\
\hline $\mathbf{9 a}$ & Diques marginais seguidos por planícies aluviais. \\
\hline $\mathbf{9 b}$ & Diques marginais seguidos por terraços ou vertentes. \\
\hline $\mathbf{9 e}$ & Confluência com coalescência de planícies fluviais. \\
\hline $\mathbf{1 0 a}$ & Depósito fluvial com vegetação arbórea ou arbustiva \\
\hline $\mathbf{1 0 b}$ & Depósito fluvial com vegetação herbácea ou ausente. \\
\hline
\end{tabular}

Figura 5 - Feições mapeadas na área de estudo com o índice de sensibilidade ambiental ao óleo correspondente

Em relação diques marginais, estes apresentam uma extensão maior e recebem constantes depósitos de sedimentos durante os períodos de cheias. O dique marginal seguido por terraço classifica-se com sensibilidade ambiental 9b, pois apresenta sensibilidade menor em comparação aos diques seguidos de planícies aluviais. Em caso de derrames de óleo nestas regiões podem ocorrer deposição e penetração do óleo junto aos sedimentos, dificultando os procedimentos de limpeza.

A feição confluência com coalescência de planícies fluviais apresenta alta sensibilidade, pois se o canal se dividir em uma série de canais menores, há uma multiplicidade de direções em que o óleo pode fluir e a probabilidade de contenção e de recuperação é dificultada (Hayes et al., 1997).

Os depósitos fluviais são constantemente alimentados por sedimentos, bem como apresentam diferentes tipos de substratos que determinam a probabilidade de permanência do óleo e abrigam maior variedade de espécies (Beaumord \& Ferreira, 2008). Além disso, os depósitos fluviais quando apresentam vegetação também possuem alta sensibilidade, pois o óleo pode aderir-se facilmente, dificultando os procedimentos de limpeza (Wieczorek, 2005). Os depósitos aluviais com vegetação herbácea são responsáveis por uma menor retenção de óleo se comparadas às áreas de vegetação arbórea e arbustiva, possuindo sensibilidade menor (10b). As áreas com vegetação arbórea e arbustiva também apresentam uma maior dificuldade nos procedimentos de limpeza, podendo aumentar o tempo de permanência do óleo (Hayes et al., 1997).

Os índices de sensibilidade estabelecidos seguem os princípios apontados por Hayes et al. (1995) os quais se baseiam na concepção de limiares geomorfológicos, definidos por Schumm (1973).

Assim, divide-se o canal fluvial em setores os quais são marcados por diferentes gradientes e, portanto, distintas energias de escoamento. Esses gradientes geram, na concepção desses autores, distintas morfologias de canal em função de diferenciadas condições de sedimentação e/ou erosão.

Na concepção de Hayes et al. (1995) as diferentes morfologias exercem forte influência na possibilidade de desenvolvimento biológico. Assim, esses autores defendem a ideia de que o mapeamento das morfologias pode indicar tanto o dinamismo do escoamento do canal, como, indiretamente, o desenvolvimento da biota, fatores determinantes na sensibilidade ao óleo. Dessa forma, cada setor apresenta variações no tempo potencial de permanência do óleo e na dinâmica da mistura do óleo na coluna de água e de sedimentos.

A partir do mapeamento realizado, foram selecionados setores significativos, que apresentaram diferentes graus de sensibilidade, os quais serão analisados visando avaliar como as características geomorfológicas podem definir respostas a acidentes envolvendo derrames de óleo.

\section{RESULTADOS E DISCUSSÕES}

Foram selecionados três diferentes setores da área de estudo para a análise de maior detalhe: o setor 1, caracterizado pela presença de margens erosivas e deposicionais, além de 
diques marginais, terraços fluviais e zonas de coalescência de canais; o setor 2, também com grande variedade de feições, apresentando um pequeno lago e confluência com coalescência de planícies fluviais e o setor 3 , com forte presença da área urbana, da cidade de Piracicaba, além da ocorrência de soleiras fluviais. No primeiro setor (Figura 6) observa-se, a partir do recorte do mapeamento geomorfológico, a presença de margens erosivas, as quais indicam uma maior energia das águas, responsáveis por processos de erosão fluvial lateral das margens côncavas.

Na sequência tem-se margens deposicionais e barras fluviais demonstrando a intensa dinâmica de movimentação dos materiais.

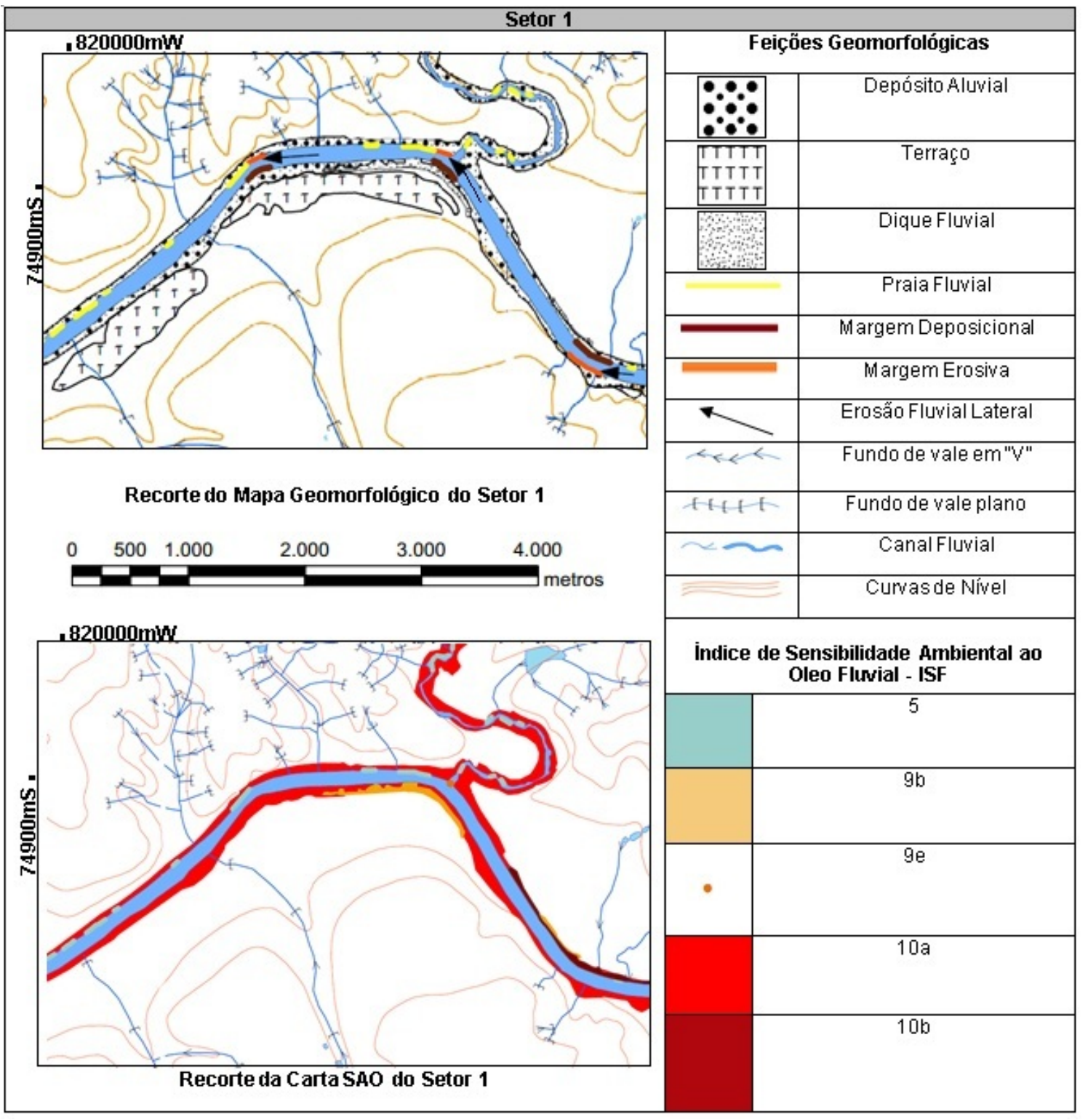

Figura 6 - Recortes do mapa geomorfológico e Carta SAO do Setor 1.

A contínua deposição de sedimentos arenosos impossibilita, em alguns trechos, junto ao rio, a estabilização de uma flora permanente, originando as barras fluviais. $\mathrm{Na}$ margem esquerda, devido à presença de um declive menor, ocorre a diminuição da energia das águas e há a presença de um dique marginal. Destaca-se ainda a presença de terraços fluviais que representam antigas planícies de inundação que foram abandonadas e surgem como patamares aplainados, de largura variada, limitados por uma ruptura de declive em direção ao curso d'água, e inúmeros canais fluviais que dissecam as vertentes e conectam-se ao rio principal.

Verifica-se a presença de um canal fluvial na margem direita do rio, mais a montante do canal principal, marcado por diversos depósitos e barras fluviais em seu curso, estes possivelmente decorrentes da diminuição da energia das águas 
ocasionada pela construção de um pequeno represamento mais a jusante do canal.

Em relação à sensibilidade ambiental do setor, observando o recorte da área, exposto na figura 7 , nota-se que ambas as margens se classificam com ISF 10 devido à presença de depósitos fluviais na extensão das mesmas. Estes são constantemente alimentados por deposições de sedimentos que, por serem inconsolidados e muitas vezes de origem arenosa, portanto permeáveis, podem armazenar o óleo, no caso de um eventual derramamento. A limpeza tende a transferir o óleo para camadas mais profundas e sedimentos novos podem recobrir os contaminados com óleo, dificultando ainda mais os processos de limpeza. Além disso, devido ao baixo hidrodinamismo de muitas destas regiões, a limpeza natural não será realizada de forma eficiente.

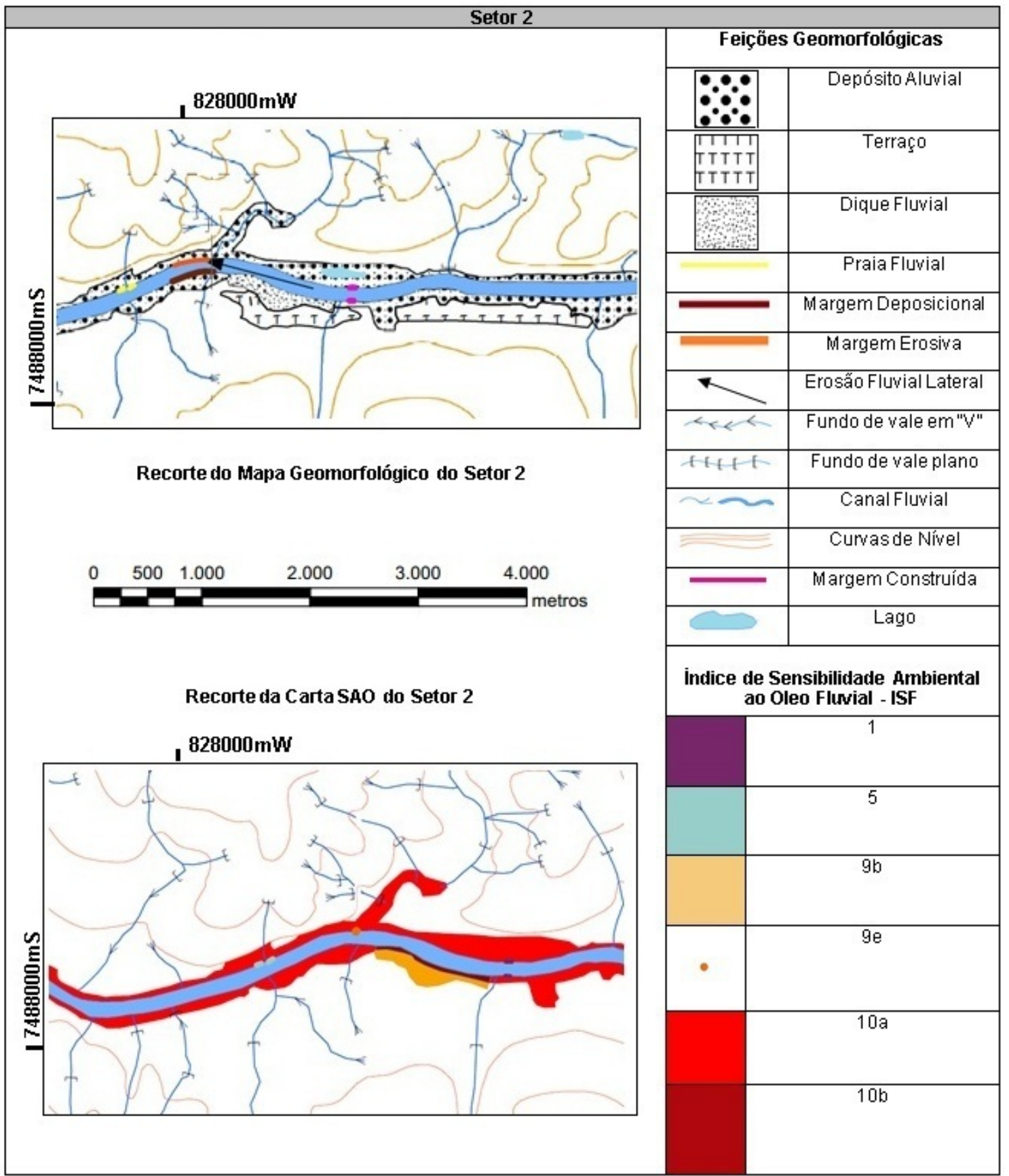

Figura 7 - Recortes do mapa geomorfológico e Carta SAO do Setor 2.

De acordo com Mendoza-Cantú et al. (2011), quanto maior a permeabilidade do solo, mais profunda será a penetração do óleo e maior será a sua persistência, sendo mais difícil a sua limpeza e reparação. Há, porém, no mesmo trecho ilustrado, pequenas faixas de barras fluviais (Figura 5), com índice inferior, equivalente a ISF 5, em decorrência de sua pequena extensão e por localizarem-se em regiões de mais fácil acesso para os 
procedimentos de limpeza (Wieczorek, 2005).

Ainda neste setor é possível observar a presença de uma confluência com coalescência de planícies aluviais, classificadas com ISF 9e, pois há risco de uma maior extensão ser atingida por meio de outros canais ligados ao rio principal. Destaca-se também a presença de um dique marginal seguido por terraço. Esta feição classifica-se com ISF 9b, pois apresenta sensibilidade menor em comparação aos diques seguidos de planícies aluviais.

Na figura 7 está ilustrado outro setor da área de estudo, caracterizado, de acordo com o mapa geomorfológico, pela presença de extensos depósitos em ambas as margens do rio, com um pequeno lago em sua margem direita.

Nota-se que, devido a menor declividade da margem esquerda do canal, ocorrem alguns terraços fluviais e um extenso dique marginal. Observa-se, na margem direita, mais a jusante do canal, a ocorrência de processos de erosão fluvial lateral e, na sequência, registra-se o surgimento de barras fluviais. Neste setor apresenta-se o início de uma ocupação urbana mais concentrada na área de estudo, com a presença de uma ponte, destacada com um traço em rosa.

A sensibilidade ambiental da área é marcada por depósitos recobertos tanto com vegetação herbácea como com vegetação arbustiva e arbórea, que apresentam ISF 10, sendo a arbustiva 10a e a herbácea 10b. A presença da vegetação dificulta a limpeza, sendo tal dificuldade agravada quando o porte arbóreo ou arbustivo impede o trânsito de equipamentos. Concomitantemente, o enraizamento retém o óleo.

O setor de confluência com coalescência de planícies fluviais apresenta ISF 9e visto que esse tipo de morfologia pode indicar possibilidades de contaminação da drenagem afluente. Já o setor de dique marginal seguido de um terraço apresenta ISF 9b, isto é, menor sensibilidade do que as áreas de depósitos recobertas por vegetação, mas ainda um alto índice em função da permeabilidade desse tipo de feição.

Já as barras fluviais classificam-se com índice 5 visto a constante circulação de água sobre essas. Ainda, a presença da ponte define índice 1, pois, de acordo com Araújo (2006), dificilmente ocorrerá um acúmulo de óleo neste tipo de estrutura, sendo facilmente lavada por jatos de água, não apresentando dificuldades em processos de limpeza.

A figura 8 mostra o terceiro setor, que se apresenta com uma ampla concentração urbana, característica da cidade de Piracicaba. Notamse estreitos depósitos fluviais, contudo há áreas em que estes depósitos são interrompidos, com a presença de área urbana e ausência de vegetação nativa.

As áreas urbanas que se estendem às margens do canal geram estruturas artificias, principalmente paredões concretados. Observam-se também no setor a presença de soleiras fluviais, mais a montante do canal. De acordo com Guerra \& Cunha (2009) e Guerra \& Marçal, (2009) a soleira classificase como uma barra de rocha dura que funciona como nível de base num ciclo de erosão; estas feições são muito importantes nos leitos fluviais, pois, por servirem de nível de base, comandam a erosão.

A presença de soleiras gera um sistema lótico, com presença de fortes correntezas no caso estudado, o que facilita o processo de limpeza natural do trecho; por este motivo, a sensibilidade destes ambientes é mais baixa (ISF 2).

Em termos de sensibilidade ambiental, a região referida apresenta-se com um índice de sensibilidade ambiental menor, excetuando os depósitos fluviais presentes. As margens construídas classificam-se com ISF 1 , pois se constituem em estruturas artificiais, não apresentando dificuldades nos procedimentos de limpeza do óleo. As soleiras fluviais classificam-se com ISF 2, pois a persistência do contaminante é normalmente de curto prazo. No caso dos óleos leves, estes têm tendência a ser removidos rapidamente pela ação das águas e evaporação (Wieczorek, 2005).

De maneira geral, a área escolhida para a realização deste estudo apresenta altos índices de sensibilidade ambiental ao óleo, pois os processos fluviais discutidos a partir dos setores apresentados se repetem ao longo de todo o trecho.

Portanto, devido à complexidade da morfologia deste setor, faz-se necessário a constituição de políticas de preservação ambiental na área no que diz respeito a acidentes envolvendo derrames de óleo. 


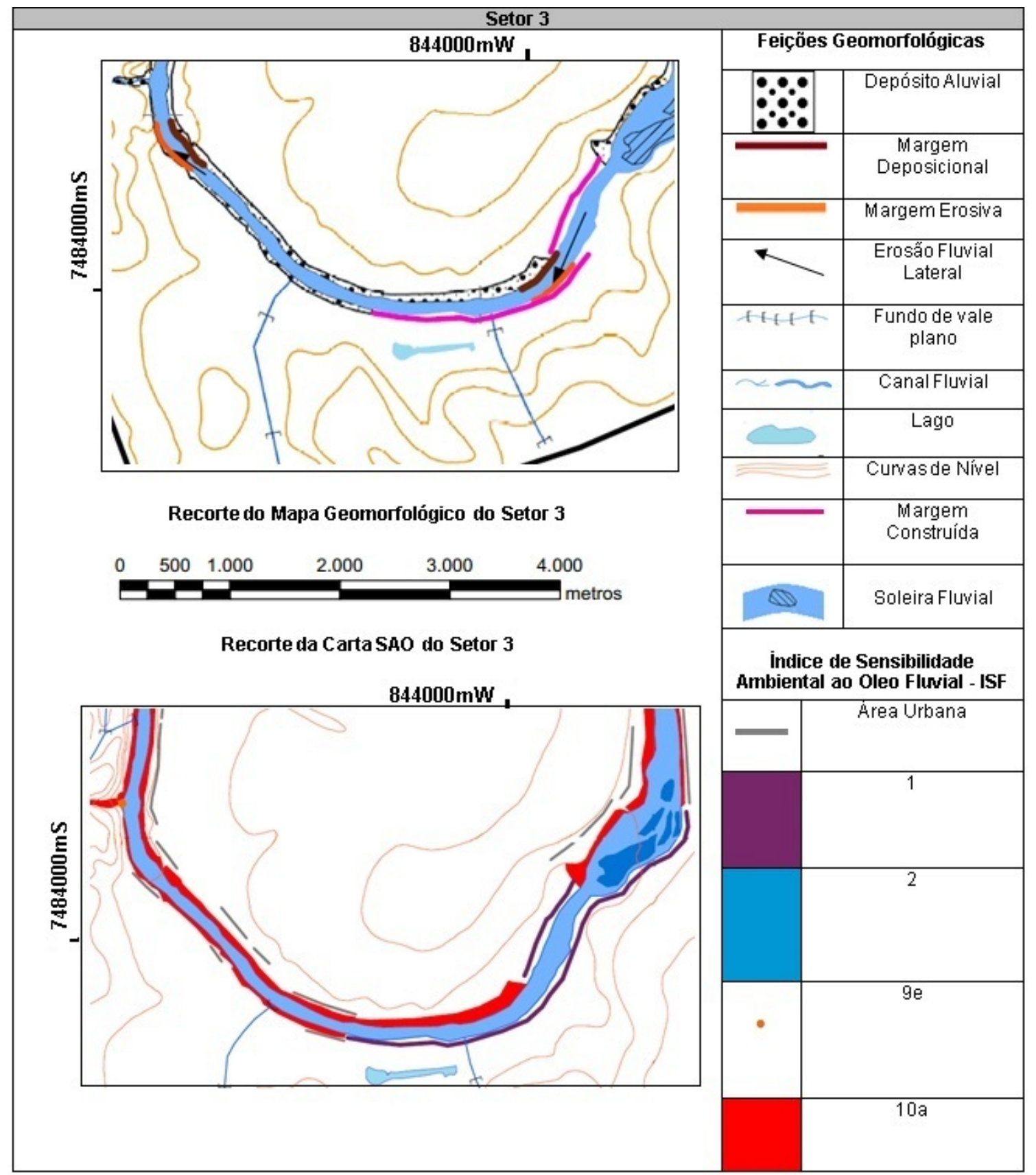

Figura 8 - Recortes do mapa geomorfológico e Carta SAO do Setor 3.

\section{CONCLUSÕES}

No presente trabalho foi proposta uma metodologia para a avaliação da sensibilidade ambiental ao óleo de cursos fluviais, por meio do mapeamento das feições geomorfológicas no interior do curso d’água e em suas margens. Foi avaliado um trecho do baixo curso do rio Piracicaba, de médio porte, com características bastante distintas do que foi realizado para os rios amazônicos por Araújo et al. (2002) e Araújo (2006).

A realização do mapeamento geomorfológico da área permitiu a avaliação da sensibilidade ao óleo das feições encontradas. Segundo Tricart
(1965), o mapeamento geomorfológico apresenta-se como uma base que direciona as pesquisas, e quando concluído, constitui-se como uma síntese dessas. Os mapeamentos geomorfológicos funcionam como subsídio para a identificação dos tipos de terreno, fator de fundamental importância à acomodação do óleo. Além disso, nos ambientes fluviais a morfologia dos terrenos tem também relação com a biota que ali se desenvolve.

A partir do mapeamento das feições geomorfológicas da área de estudo, e consequente avaliação de sua sensibilidade ao óleo, constatou- 
se que a região apresenta elevada sensibilidade devido à presença de amplas planícies, as quais possibilitam um aumento da área atingida pelo óleo em caso de acidentes. Devido à presença de depósitos aluviais distribuídos pela margem de todo o canal, estes possibilitam uma intensa miscigenação e incorporação do óleo junto aos sedimentos. A presença de inúmeros canais afluentes do canal principal também representa um alto grau de sensibilidade, pois permite uma multiplicidade de direções em que o óleo pode fluir, dificultando os processos de contenção, limpeza e recuperação.

Portanto, a partir do exposto, pode-se afirmar que a área do presente estudo apresenta diversas regiões que devem ser priorizadas em caso de acidentes envolvendo derrames de óleo, e poucas áreas que podem ser utilizadas como áreas de sacrifício, caracterizadas pelos locais que apresentam baixos índices de sensibilidade.

As áreas correspondentes aos setores 1 e 2 apresentam-se como regiões com maior índice de sensibilidade ambiental ao óleo, pois possuem feições com sensibilidade alta, como os depósitos fluviais com vegetação arbórea e herbácea; portanto são áreas que devem ser priorizadas em caso de acidentes.

O setor 3 apresenta uma região com baixa sensibilidade ambiental, devido à presença de margens construídas e soleira fluvial, cujos índices de sensibilidade são menores, desta forma, esta área pode ser utilizada como área de sacrifício em casos de derrames.

Por fim, a realização do mapeamento da sensibilidade a derrames de óleo a partir de parâmetros geomorfológicos constitui-se em uma importante ferramenta, que contribui para o desenvolvimento e produção de cartas de sensibilidade ambiental ao óleo (Cartas SAO). Essas cartas são imprescindíveis para o desenvolvimento de procedimentos para conter derrames de óleo em caso de acidentes.

Cabe também ressaltar que a caracterização geomorfológica, realizada por meio de imagens orbitais, no caso as imagens do SPOT 5, com 2,5 $m$ de resolução espacial, se constitui em interessante alternativa para os ambientes fluviais de um país de dimensões continentais como o Brasil, onde ocorre 12\% da água doce do planeta.

Os resultados obtidos mostraram ser possível mapear as feições geomorfológicas fluviais, com sua posterior classificação de sensibilidade ambiental ao óleo. Porém, estes estudos podem ser aprimorados com campanhas de campo, em áreas de maior complexidade.

Essa pesquisa visa também contribuir para estudos futuros, apresentando técnicas que facilitem a identificação das feições fluviais sensíveis ao óleo, a elaboração e análise de Cartas SAO, visto que as publicações nacionais e internacionais a respeito de sensibilidade ambiental ao óleo em ambientes fluviais apresentam lacunas.

Devido a estas lacunas, adaptações foram necessárias para a classificação dos ambientes da área de estudo. Diferentemente do ambiente costeiro, há muito que se propor e estudar com relação ao mapeamento da sensibilidade ambiental ao óleo nos ambientes fluviais no Brasil e no mundo.

\section{REFERÊNCIAS}

ARAUJO, S.I. Mapas de Sensibilidade Ambiental a Derrames de Óleo: Ambientes costeiros, estuarinos e fluviais. Rio de Janeiro: CENPES/Petrobras, 166p., 2006.

ARAUJO, S.I.; MUEHE, D.C.E. H.; SILVA, G.H. Manual Básico para elaboração de Mapas de Sensibilidade Ambiental a Derrames de Óleo no Sistema Petrobras: Ambientes Costeiros e Estuarinos. Rio de Janeiro: CENPES/Petrobras, 133p., 2002.

AYOADE, J.O. Introdução a Climatologia dos Trópicos. São Paulo, Editora: Bertrand Brasil, 332p., 2012.

BEAUMORD, A.C. \& FERREIRA, M.F. Mapeamento da sensibilidade ambiental a derrames de óleo nos cursos de água da bacia do rio Canhanduba, Itajaí, SC. Santa Catarina: UNIVALI, Universidade do Vale do Itajaí, 2008.

BRAUN, O.P.C. \& OLIVEIRA, W.J. Mapas de sensibilidade ambiental de faixas de dutos terrestres. In: SEMINÁRIO DE ATENDIMENTO A EMERGÊNCIAS EM NÍVEL REGIONAL - REGIÃO SÃO PAULO E CENTRO OESTE, 2003, São Paulo. Anais...São Paulo, 2003.

ABRAL, J.B.P. Utilização de técnicas de segmentação e correlação de spearman em imagens TM para o estudo da concentração de sedimentos em suspensão no Reservatório de Barra Bonita - São Paulo - Brasil. GeoFocus (Artículos), n. 3, p. 235-267, 2003

COSTA, D.M; RIEDEL, P.S; CUNHA, C.M.L; ZAMBON, A.C. Utilização do Modelo Orientado à Representação do Pensamento Humano (MORPH) no estabelecimento do Índice de Sensibilidade Fluvial (ISF): uma proposta de contribuição à Classificação da Sensibilidade Ambiental ao Óleo. Porto Alegre, Pesquisas em Geociências, v. 42, n. 1, p. 25-44, 2015.

CUNHA, C.M.L. A Cartografia do Relevo no Contexto da Gestão Ambiental. Rio Claro, 2001. 128p. Tese (Doutorado em Geociências e Meio Ambiente) - Instituto de Geociências e Ciências Exatas, Universidade Estadual Paulista.

GUERRA, A.J.T. \& CUNHA, S.B. Geomorfologia: Uma atualização de bases e conceitos. Rio de Janeiro: Bertrand Brasil, 479p., 2009.

GUERRA, A.J.T. \& MARÇAL, M.S. Geomorfologia Ambiental. Rio de Janeiro: Bertrand Brasil, 190p., 2009.

HAYES, M.O.; MICHEL, J.; DAHLIN, J.A. Identifying and 
mapping sensitive resources for inland area planing. In: INTERNATIONAL OIL SPILL CONFERENCE, Washington, 1995. Proceedings...Washington: American Petroleum Institute Publication, n. 4651, p. 365-371.

HAYES, M.O.; MICHEL, J.; MONTELLO, T.M. The Reach Sensitivity Index (RSI) for Mapping Rivers and Streams. In: INTERNATIONAL OIL SPILL CONFERENCE, Washington, 1997. Proceedings... Washington: American Petroleum Institute Publication, n. 4651, p. 343-350.

IPT - INSTITUTO DE PESQUISAS TECNOLÓGICAS DO ESTADO DE SÃO PAULO. Mapa Geológico do Estado de São Paulo. São Paulo, 2 v. 1981.

JENSEN, J.R.; HALLS, N.J.; MICHEL, J. A system approach to environmental sensitivity Index (ESI) mapping for oil spill contingency planning and response. Photogrammetric Engineering \& Remote Sensing, v. 64, n.10, p. 1003-1014, 1998.

MINISTÉRIO DO MEIO AMBIENTE. Especificações e Normas técnicas para a Elaboração de Cartas de Sensibilidade Ambiental para Derrames de Óleo. Rio de Janeiro: CENPES/Petrobras, 2002.

MENDOZA-CANTÚ, A.; HEYDRICH, S.C.; CERVANTES, I.S.; OROZCO, O.O. Identification of environmentally vulnerable areas with priority for prevention and Management of pipeline crude oil spills. Journal of Environmental Management, n. 92, p. 1706-1713, 2011.

PASCHOAL, L.G.; CONCEIÇÃO, F.T.; CUNHA, C.M.L. Utilização do ArcGis 9.3 na elaboração de simbologias para mapeamentos geomorfológicos: Uma aplicação na área do Complexo Argileiro de Santa Gertrudes/SP. In: SIMPÓSIO
NACIONAL DE GEOMORFOLOGIA, VIII, 2010, Recife. Anais...Recife, p. 1-13. 2010.

PAVLOPOULOS, K.; EVELPIDOU, N.; VASSILOPOULOS, A. Mappin Geomorphological Environments. Berlin: Springer Science \& Business Media, 236p., 2009.

SCHUMM, S.A. Geomorphic thresholds and the complex response of drainage systems. In: Morisawa, M. (Editor), Fluvial Geomorphology. Publications in Geomorphology. State University of New York, Binghamton, p. 299-310, 1973.

TRICART, J. Principes et méthodes de la géomorphologie. Paris: Masson et Cie, 496p. 1965.

VERSTAPEN, H.T \& ZUIDAM, R.A. ITC system of geomorphological survey. Manuel Itc Textbook, Nertherlands, v. VII, 49p., 1975.

WIECZOREK, A. Estudo da sensibilidade a derrames de óleo do rio Atibaia à jusante do polo petroquímico de Paulínia. Relatório de Projeto de Pesquisa. Programa de Auxílio à Pesquisa. Fundação Mapfre, 156p., 2005.

ZENGEL, S; HAYES, M.O; MICHEL, J; WHITE, M. Integrated Planning From the Mountains to the Sea Environmental Sensitivity Mapping In the Caribbean. Columbia: Research Planning Inc, 2001.

Submetido em 20 de setembro de 2016 Aceito em 20 de janeiro de 2018 